\title{
QUANTITATIVE ANALYSIS OF ULTRASTRUCTURAL CHANGES IN DEVELOPING RAT CARDIAC MUSCLE DURING NORMAL GROWTH AND DURING ACUTE VOLUME LOAD
}

\author{
KaZUYASU NaKata, M.D.
}

$\mathrm{C}$ LOSURE of the ductus arteriosus and the foramen ovale happens after the beginning of pulmonary respiration at birth! ${ }^{1-3}$ According to Dawes' study in fetal circulation, ${ }^{4}$ the volumes of blood flow through the atria or ventricles are not the same, and after birth these volumes become the same after the ductus arteriosus and foramen ovale close. At this time, the cardiac output also increases $5-8$ Thus, it is interesting to study the fine structures of both atrial and both ventricular myocardiums during the abrupt changes in blood circulation at birth. However, studies about the differences in fine structures of developing cardiac muscle among both atria and both ventricles have not been performed at all. Therefore, I examined the ultrastructural changes of both atrial and both ventricular myocardiums during normal growth and analysed them quantitatively by using the mathematical technique of point counting.,10 Also, for the fine structures of the cardiac muscle, I studied the differences between young post-natals and adults during volume load, and then I analysed them quantitatively.

\section{MATERIALS AND METHODS}

Myocardium was taken from both atria and both ventricles of Wistar-strain rats. Fifteen stages of development were studied by electron microscopy in newborn rats and at $1,2,3,4,5$,

Key Words:

Developing rat cardiac muscle

Electron microscopy

Quantitative analysis

Acute volume load
$6,7,14,21,30,60,90,120$, and 180-day intervals after birth.

The hearts of post-natal rats younger than 7 days were quickly dissected out and then placed in ice-cold formaldehyde-glutaraldehyde fixative buffered with $0.2 \mathrm{M}$ cacodylate buffer at $\mathrm{PH}$ 7.6.1 They were next postfixed with 1 percent osmium tetroxide in $0.2 \mathrm{M}$ cacodylate buffer. The hearts from rats older than 7 days were placed in ice-cold 5 percent glutaraldehyde in 0.1

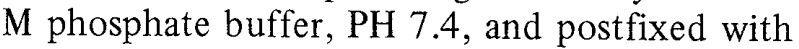
1 percent osmium tetroxide in $0.1 \mathrm{M}$ phosphate buffer. The tissues were dehydrated in a graded series of cold alcohols, embedded in Epon 812, and then cut thinly by a microtome. The sections were next stained with uranyl acetate and lead citrate, and examined by a electron microscope. A minimum of five rats were used per each stage.

Random samples (a minimum of five from each chamber in each stage) were taken from both atria and both ventricles. 8 to 12 electron micrographs of different muscle cells were taken from each sample in each stage; thus a total of 40 to 60 micrographs from each chamber per each stage were accumulated. The original magnification was $\times 2000$ to $\times 3000$. Twenty electron micrographs from each chamber per each stage, including the cells cut transversely or obliquely, were selected for quantitative analysis by the point counting technique. Quantitative analysis was performed for mitochondria, myofibrils and glycogen particles. Also, micrographs at higher magnification $(X 4000$ to $X 10000)$ were prepared for detailed observations.

Furthermore, by intravenously injecting blood

(Received on April 11, 1977; Accepted on June 30, 1977)

Department of Pediatrics, Kyoto Prefectural University of Medicine (Professor: Tomoichi Kusunoki, M.D.), Kawaramachi Hirokoji, Kamigyo-ku, Kyoto, Japan

Address for reprints: Kazuyasu Nakata, M.D., BH Box 137, Department of Medicine, University of Chicago, 950 East 59th Street, Chicago, Illinois, 60637 U.S.A. 


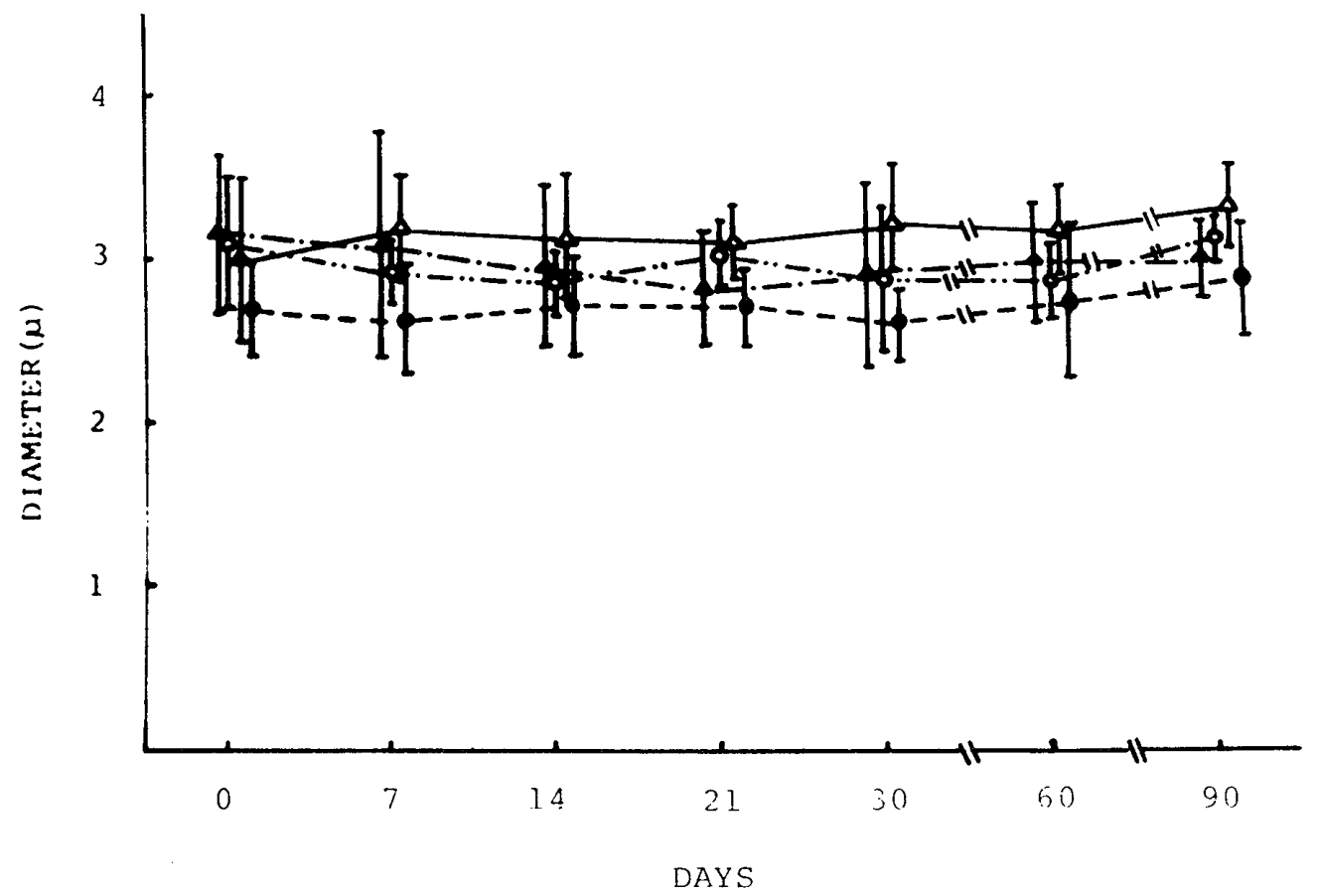

Fig.1. Alteration in minimum diameter of nuclei during normal growth. Diameter in $\mu \mathrm{m}$ is plotted against age.

Vertical lines represent standard error. Nuclear diameters do not alter significantly with increasing age, and those of both atria and both ventricles are almost same.

$(-. .-)$ right atrium; (- ) left atrium; (-) right ventricle; (-.-) left ventricle.

equalling the whole blood volume of each rat for 30 minutes, volume load was performed on each rat at the ages of 0 (1-2 hours after birth), 1, 2, $3,4,5,6,7,14,21,30,60,90,120,150$, and 180 days. The same was done to 6-month-old rats, except that the injected amount was twice as much as the whole blood volume. Five rats were used per each stage. 2 hours after volume load, they were killed with a blow on the head. Next, the hearts were exposed, and while still beating, small pieces of the left ventricle were removed, fixed, and embedded by the method described above. The specimens were similarly examined by electron microscopy.

In order to perform quantitative analysis by the pointcounting technique, a total of 40 to 60 electron micrographs of different muscle cells were taken from each left ventricle of five rats at the ages of 0,7 , and 90 days. The original magnification was $\times 2000$ to $\times 3000$. Twenty electron micrographs, among them which included the cells cut transversely or obliquely, were selected for quantitative analysis by the pointcounting technique.

\section{RESULTS}

As shown graphically in Fig. 1, the minimum diameter of the nuclei in both atria and both ventricles are not great altered to become significantly different throughout the developmental periods. As shown graphically in Fig. 2, from birth the cell diameter gradually increases in both atria and both ventricles with increasing age. At the perinatal period, the cell diameters are almost the same in the right atrium and right and left ventricle, but that of the left atrium is significantly smaller. The cell diameters of the right atrium and right ventricle are not significantly altered at the 7th day after birth, but that of the left atrium increases markedly in the same period and becomes equal to that of the right atrium or right ventricle. Also, the cell diameter of the left ventricle increases markedly. The cell diameters of both atria and both ventricles increase prominently by the 21 st day after birth. For the two myocardia, this increase is more prominent in the ventricular than in the atrial. Also, the cell diameters of both ventricles in adult rats are larger than those in 21-day-old rats. This tendency to be large is more prominent in the ventricular muscle, being especially more marked in the left ventricle. 


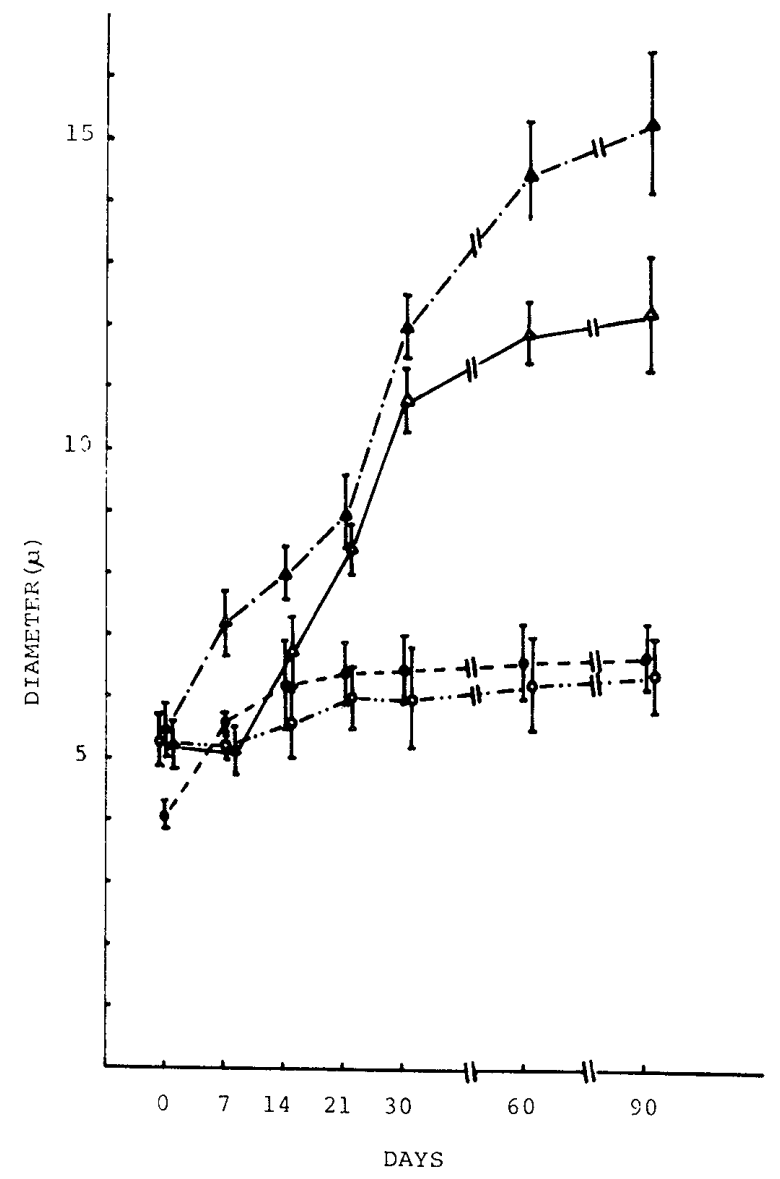

Fig.2. Alteration in cell diameter of both atria and both ventricles during normal growth. Diameter in $\mu \mathrm{m}$ is plotted against age.

Vertical lines represent standard error. The cell diameter gradually increases in both atria and both ventricles with increasing age. This tendency to be large is more prominent in the ventricular muscle, being especially more marked in the left ventricle.

(-..-) right atrium; (--) left atrium; $(-)$ right ventricle; $(-\cdot-)$ left ventricle.

Next I examined the intracellular structure. Compared with adult rats, the cells in both atria of young post-natal rats contained more ribosomes, glycogen particles and rough-surfaced endoplasmic reticulums, but fewer mitochondria and myofibrils. (Fig. 3,4) The myofibrils were not yet regularly aligned in the myocardium of young post-natal rats. The differences in intracellular structures between right and left atrium were not seen. Similarly, compared to adult rats, the myocardial cells in both ventricles of young post-natal rats contained more ribosomes, glycogen particles and rough-surfaced endoplasmic reticulums, but fewer mitochondria and myofibrils. Differences in intracellular structures between right and left ventricle could not be found (Fig. 5).

Compared with young post-natal rats, the myocardial cells of both atria in 7-day-old rats contained better-developed and increased mitochondria and myofibrils, but fewer ribosomes, glycogen particles and rough-surfaced endoplasmic reticulums. Differences in intracellular structures between right and left atria were not seen. For both ventricles, findings were the same as above.

Further, mitotic division was observed in the right ventricular muscle cells of an 8-day-old rat. (Fig. 6) In this cell during mitotic division, chromosomes were observed with many ribosomes, glycogen particles, and smooth-surfaced endoplasmic reticulums, but with fewer mitochondria and poorly-developed myofibrils. This finding demonstrates that cellular proliferation by mitotic division happens even in 8-day-old rats.

After this period, myocardial cells develop rapidly and mature greatly with increasing age. Finally, when rats reach the age of 1 month, they have almost the same intracellular structure as adults (Fig. 7).

Next, by the point-counting technique, I performed quantitative analysis of the intracellular structures in both atrial and both ventricular muscle cells. Three rat groups; 0,7 , and 90-days, were examined. In these groups, for the three main intracellular components, i.e., mitochondria, myofibril, and glycogen particles, quantitative analysis was performed on the myocardial cells.

As seen in Fig. 8, the total area occupied in the sarcoplasm by mitochondria in the right atrium increases significantly from day $0(1-2$ hours after birth) to day $90(\mathrm{P}<0.05)$. The content of myofibrils increases significantly from day 0 or day 7 to day $90(\mathrm{P}<0.01)$. Glycogen particles decrease significantly from day 0 to day $90(\mathrm{P}<0.05)$.

The total area occupied in the sarcoplasm by mitochondria in the left atrium increases significantly from day 0 to day $7(\mathrm{P}<0.05)$, and to day $90(\mathrm{P}<0.01)$. The content of myofibrils increases prominently from day 0 or day 7 to day $90(\mathrm{P}<0.01)$. Glycogen particles decrease significantly from day 0 to day $90(\mathrm{P}<0.05)$.

As seen in Fig. 9, in the right ventricular myocardium, mitochondria increase significantly from day 0 to day $90(\mathrm{P}<0.01)$, and from day 7 to day $90(\mathrm{P}<0.05)$. The content of myofibrils increases significantly from day 0 to day $90(\mathrm{P}<$ 0.01 ). Glycogen particles decrease significantly 


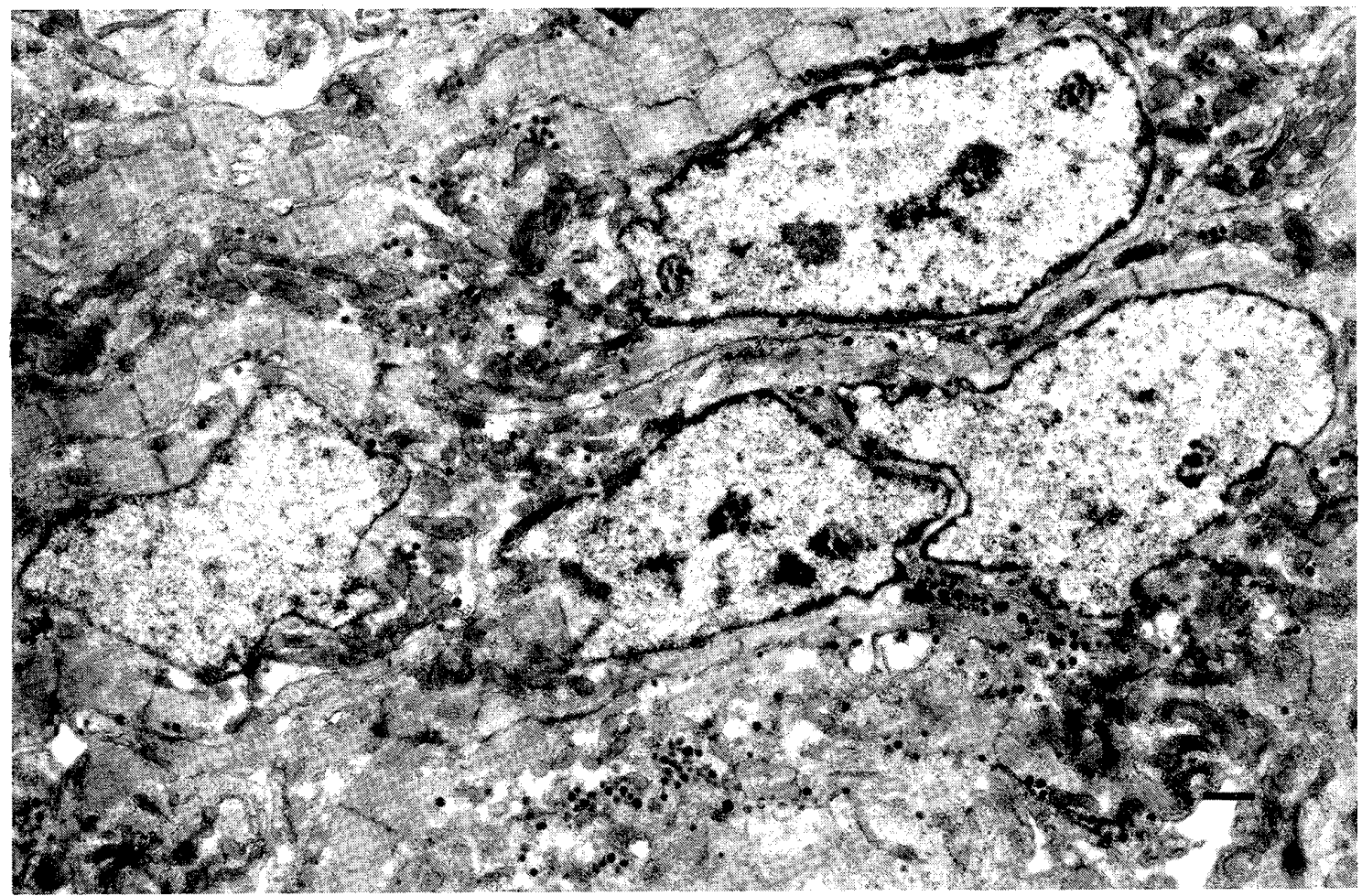

Fig.3. Electron micrograph of right atrial myocardial cell of 1-day-old rat. Many ribosomes, glycogen particles and rough-surfaced endoplasmic reticulums are seen. Myofibrils are neither sufficiently developed nor yet regularly aligned. $\times 5000$. Bar $=1 \mu \mathrm{m}$.

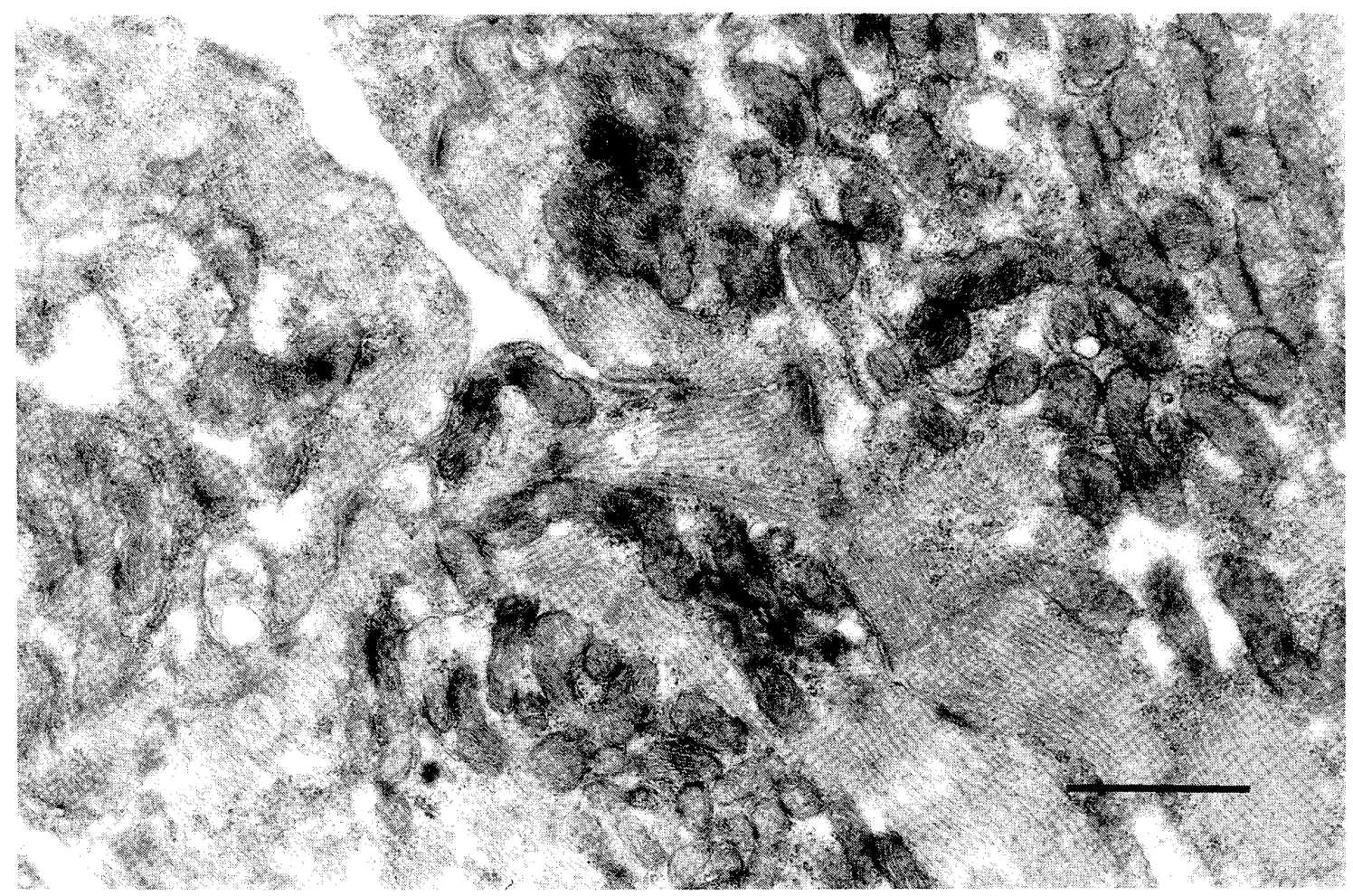

Fig.4. Electron micrograph of left atrial myocardial cell of 1-day-old rat. Many ribosomes, glycogen particles and rough-surfaced endoplasmic reticulums are seen. Myofibrils are neither sufficiently developed nor yet regularly aligned. $\times 18000, \mathrm{Bar}=1 \mu \mathrm{m}$. 


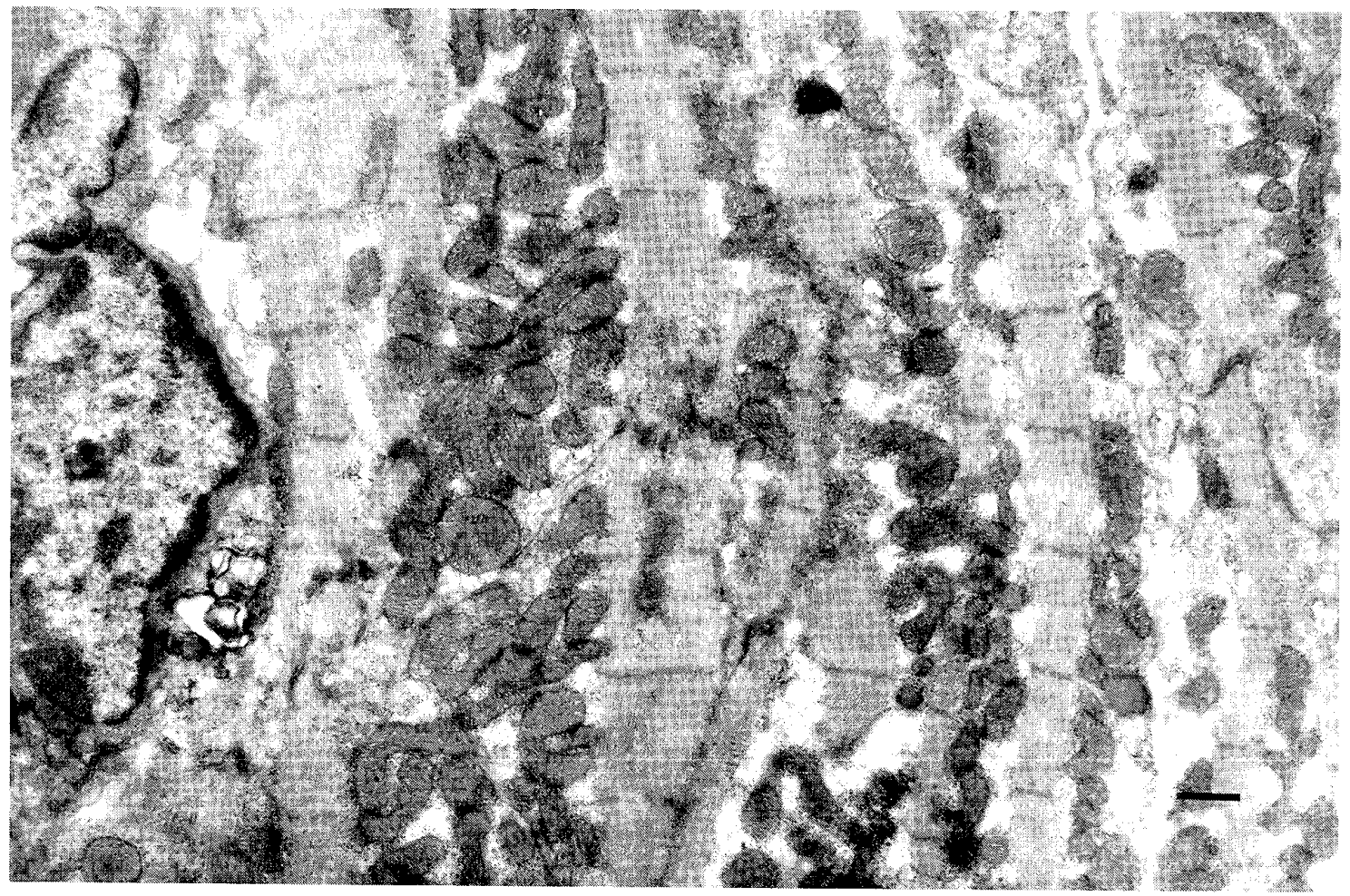

Fig.5. Electron micrograph of right ventricular myocardial cell of 2-day-old rat. Many glycogen particles are seen. $\times 7000$. Bar $=1 \mu \mathrm{m}$.

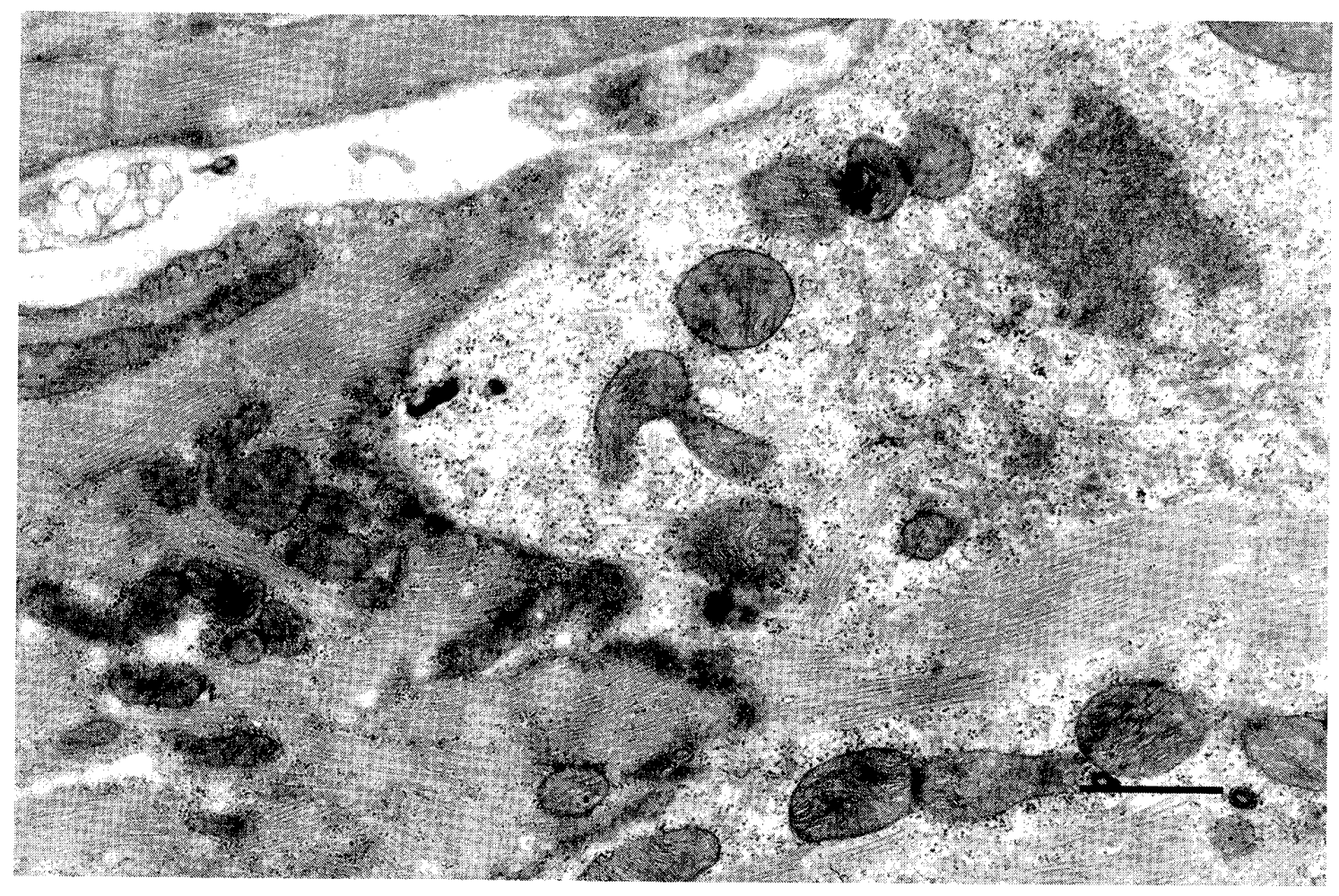

Fig.6. Electron micrograph showing mitotic division in right ventricular muscle cells of an 8-day-old rat. A chromosome is found with many ribosomes, glycogen particles and smooth-surfaced endoplasmic reticulums, but with few mitochondria and poorlydeveloped myofibrils. $\times 14000$. Bar $=1 \mu \mathrm{m}$. 


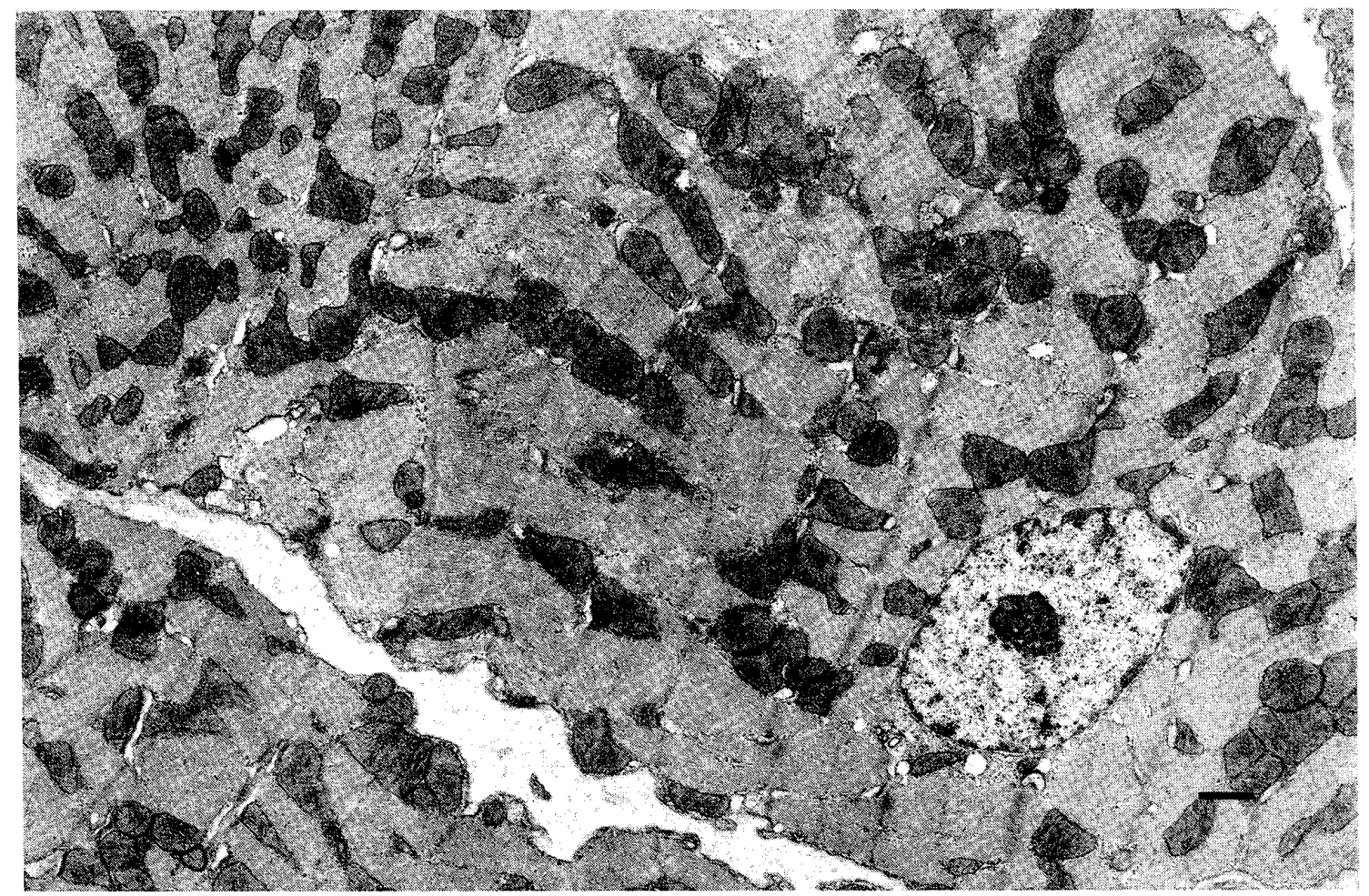

Fig.7. Electron micrograph showing left ventricular myocardium of 1 -month-old rat. Welldeveloped mitochondria and myofibrils are seen. $\times 5000$. Bar $=1 \mu \mathrm{m}$.

from day 0 or day 7 to day $90(\mathrm{P}<0.01)$.

In the left ventricular myocardium, the content of mitochondria increases significantly from day 0 to day 7 or to day $90(\mathrm{P}<0.01)$, and it increases similarly from day 7 to day $90(\mathrm{P}<$ $0.05)$. The content of myofibrils increases from day 0 to day $90(\mathrm{P}<0.01)$, and increases from day 7 to day $90(\mathrm{P}<0.05)$. Glycogen particles decrease significantly from day 0 to day 7 or to day $90(\mathrm{P}<0.01)$.

Next I made a comparative study on the differences in fine structures among both atrial and both ventricular myocardiums. The total areas occupied in the sarcoplasm by mitochondria are almost the same in both atrial and both ventricular myocardiums at day 0 , i.e. the mean percentages are 23 to $27 \%$. The contents of myofibrils are almost the same in the four cardiac chambers. Namely, the mean volume percentages of myofibrils are 44 to $48 \%$. Similarly, the mean percentages of glycogen particles in the sarcoplasm are 14 to $18 \%$, without significant differences.

At day 7, the mean total areas occupied in the sarcoplasm by the mitochondria are 30 to $31 \%$, without significant differences among the four cardiac chambers. Similarly the mean contents of myofibrils are 47 to $49 \%$, without significant differences in the four chambers.

In the rat cardiac muscle at day 90 , the mean total areas occupied in the sarcoplasm by mitochondria are 32 to $36 \%$, without significant differences in the four chambers. The mean contents of myofibrils are 53 to $58 \%$, without significant differences in the four chambers. Also the mean contents of glycogen particles are without significant differences in the four chambers.

In summary, the cell diameter of the left atrial cardiac muscle at day 0 is slightly smaller than those of the right atrial or both ventricular cardiac muscles at the same age. However, at day 7 , it becomes equal to the diameters of the right atrial and right ventricular muscles. The cell diameters of cardiac muscle become larger with increasing age. This tendency is more prominent in the ventricular myocardium than in the atrial, being, especially prominent in the left ventricular cardiac muscle. In spite of the increasing cell diameters, the minimum diameters of the nuclei are the same in both atria and both ventricles, also are not significantly altered throughout the developing periods.

The two main intracellular components, mitochondria and myofibrils, increase in the four 

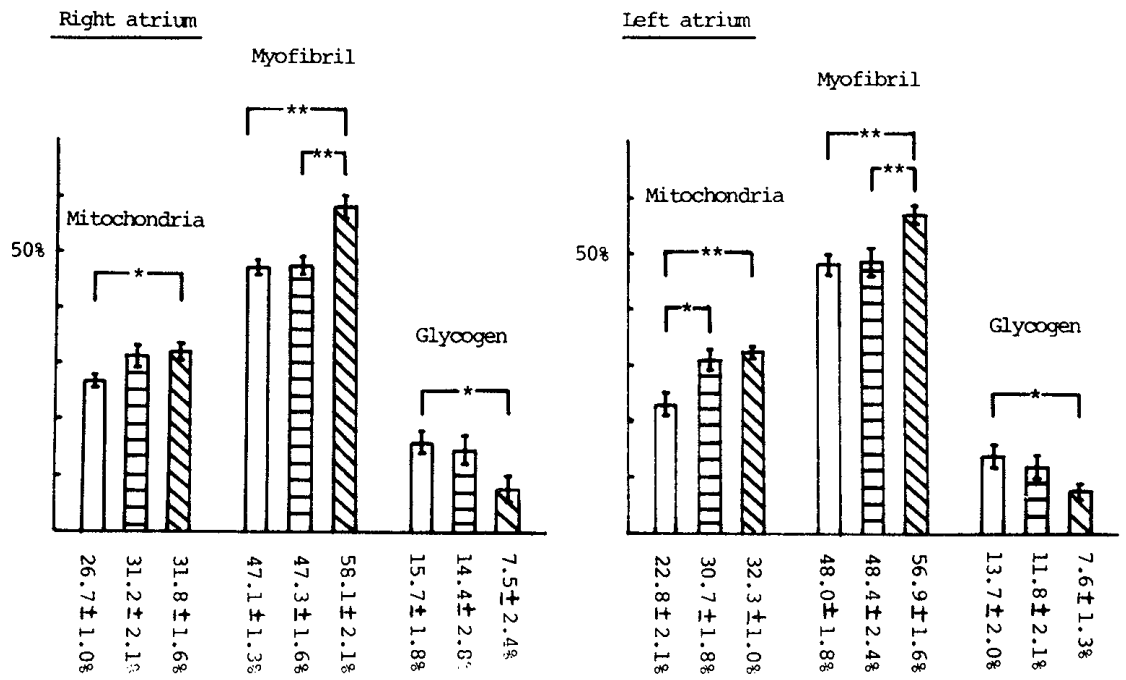

Fig.8. Morphometry of mitochondria, myofibrils and glycogen particles in right and left atrial myocardiums during normal growth. Mitochondria and myofibrils increase, also glycogen particles decrease in both atria throughout the developing periods with the same percentages of contents.

Short vertical lines represent standard error.

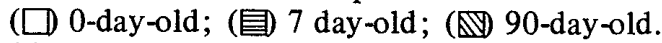
${ }^{* * P}<0.01 ; * \mathrm{P}<0.05$
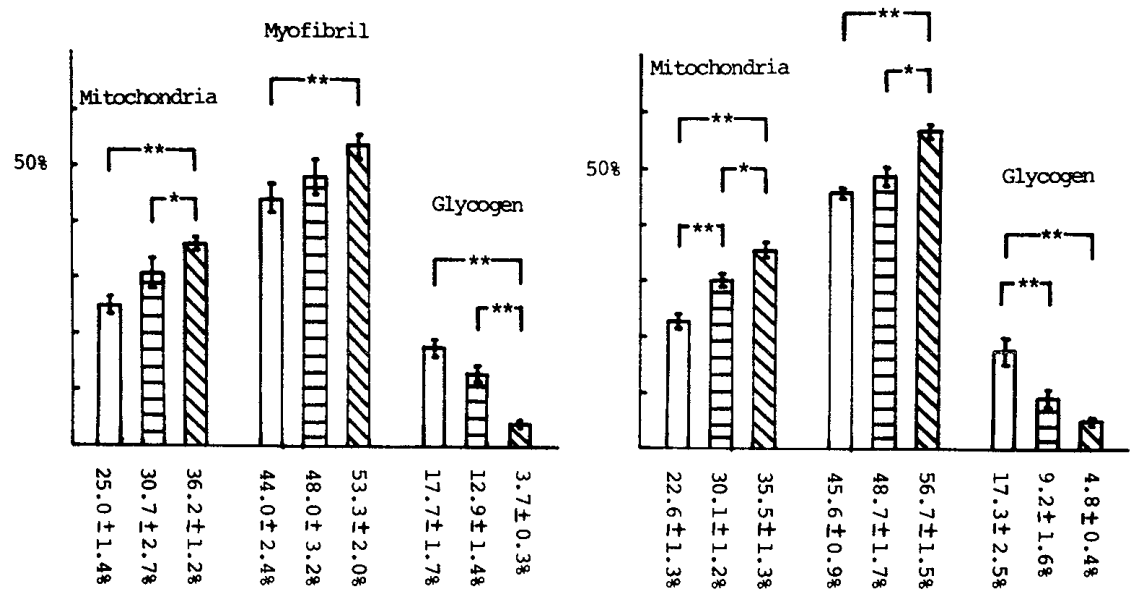

Fig.9. Morphometry of mitochondria, myofibrils and glycogen particles in the right and left ventricular myocardiums during normal growth. Mitochondria and myofibrils increase, also glycogen particles decrease in both ventricles throughout the developing periods with the same percentages of contents.

Short vertical lines represent standard error.

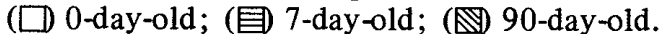
$* * \mathrm{P}<0.01 ; * \mathrm{P}<0.05$. 


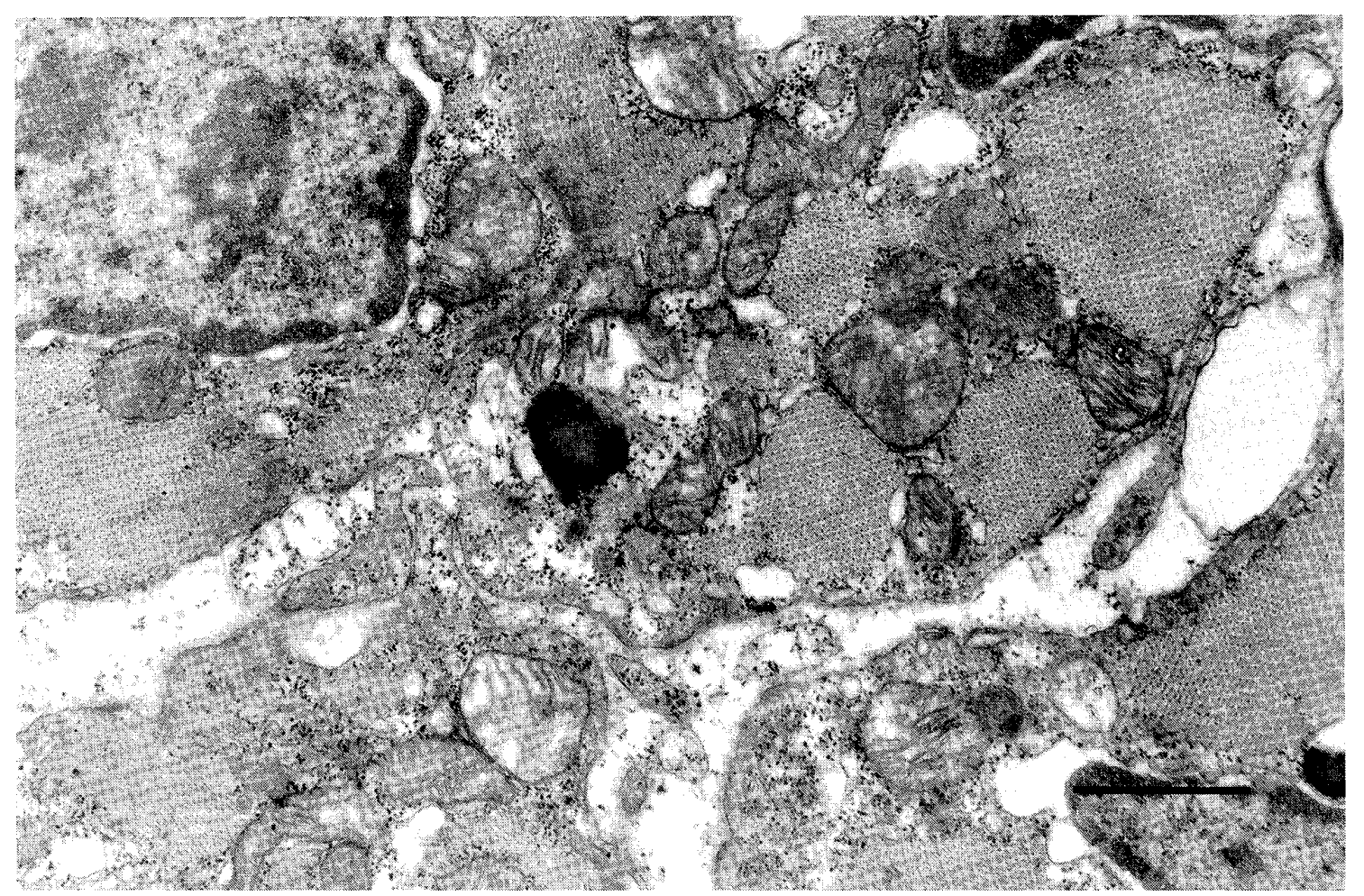

Fig.10. Electron micrograph showing left ventricular myocardial cell of a 1-day-old rat during acute volume load. Widespread mitochondrial destruction, myocardial edema and decreased glycogen granules are found markedly. $\times 18000$. Bar $=1 \mu \mathrm{m}$.

chambers throughout the developing periods with the same percentages of contents. Also, glycogen particles decrease in the four chambers throughout the same periods. However, between the atrial and ventricular cells, there were some differences in the intracellular organs. Namely, mitochondria in the atrial cells were rich near the nuclear poles, and they were less regularlyarranged than in the ventricular cells. Further, the intercalated discs in young post-natal rats were less complex than those in adult rats, and the atrial cells had less complicated intercalated discs than in the ventricular cells. A transverse tubular system appeared in the myocardial cells between the tenth and fourteenth days of postnatal life, but was seldom found in atrial cells. Also numerous atrial "specific" granules were found in the atrial cells, but such were found only occasionally in the ventricular myocardium.

Next, volume load by blood equalling the whole blood volume was performed on the rats by intravenous injection for 30 minutes. The rats were killed 2 hours after this volume load, and the left ventricular myocardiums were examined by the above method.

Widespread mitochondrial destruction, myocardial edema and decreased glycogen granules were found markedly in the myocardiums of young post-natal rats (Fig. 10). However, such changes were found in less degrees in the left ventricular muscle at day 7 . After the same overload, the myocardium of adult rats showed slight damages, and the numerous enlarged mitochondria with increased number of cristae occupying a large intracellular space (Fig. 11, 12). However, in adult rats, when volume load by intravenous injection of blood equalling twice as much as the whole blood was performed, marked mitochondrial damages and intracellular edema were found in the myocardiums (Fig. 13).

Quantitative analysis by the point-counting technique was similarly performed for the left ventricular myocardium (Fig. 14). In spite of mitochondrial damages after volume load, there were no significant differences in volume percentages of mitochondria found between the control group and volume load group at day 0 . Such a fact shows that some parts of the mitochondria disappear after severe damages. The content of glycogen particles in that myocardium decreased significantly after volume load $(\mathrm{P}<$ 0.01). In 90-day-old rat cardiac muscle the content of mitochondria increased significantly after volume load $(\mathrm{P}<0.01)$. This fact shows 


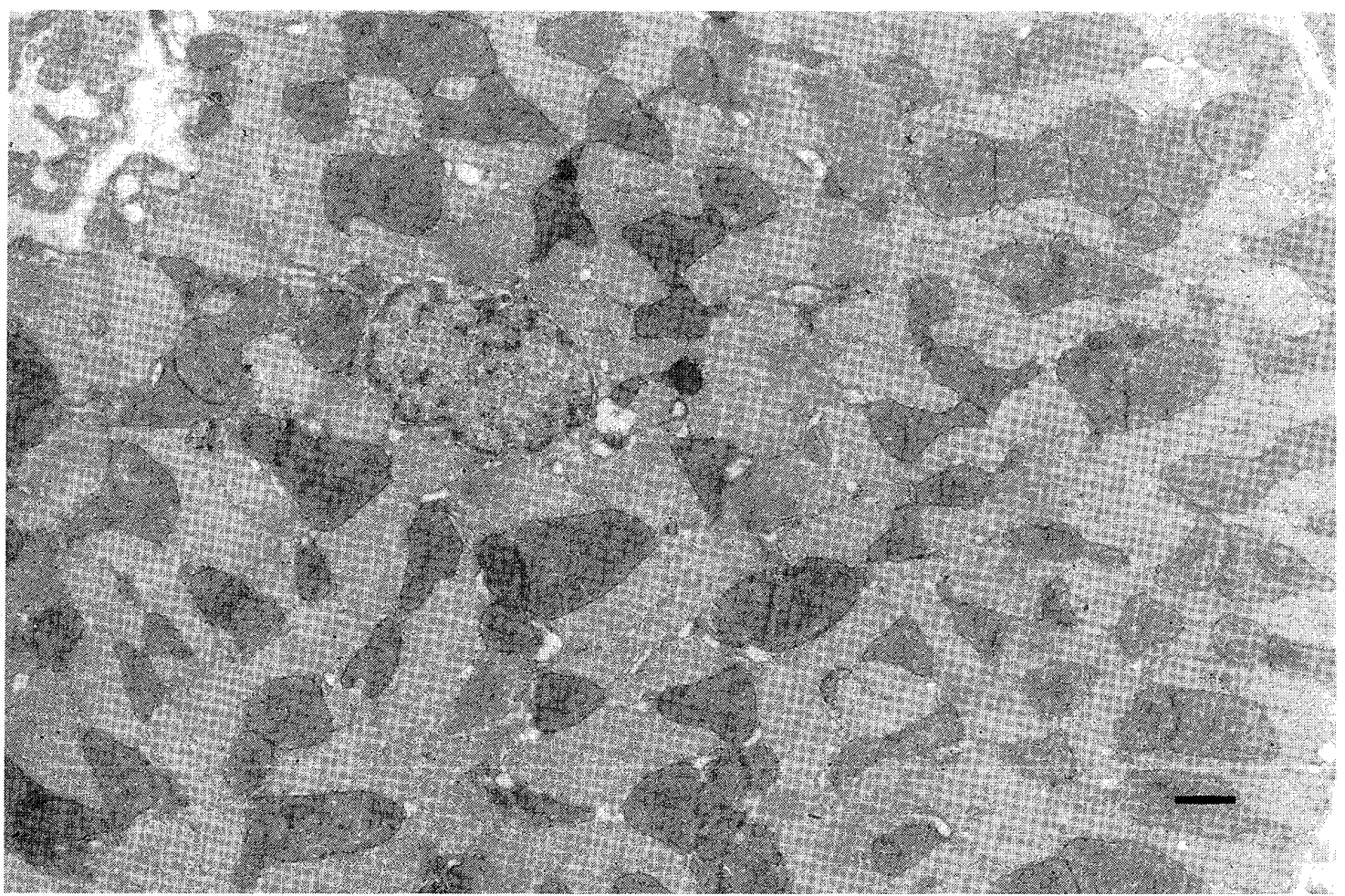

Fig.11. Electron micrograph showing left ventricular myocardial cell of an adult rat during acute volume load. There are no marked damages in myocardial cells. $\times 6000$. Bar $=1 \mu \mathrm{m}$.
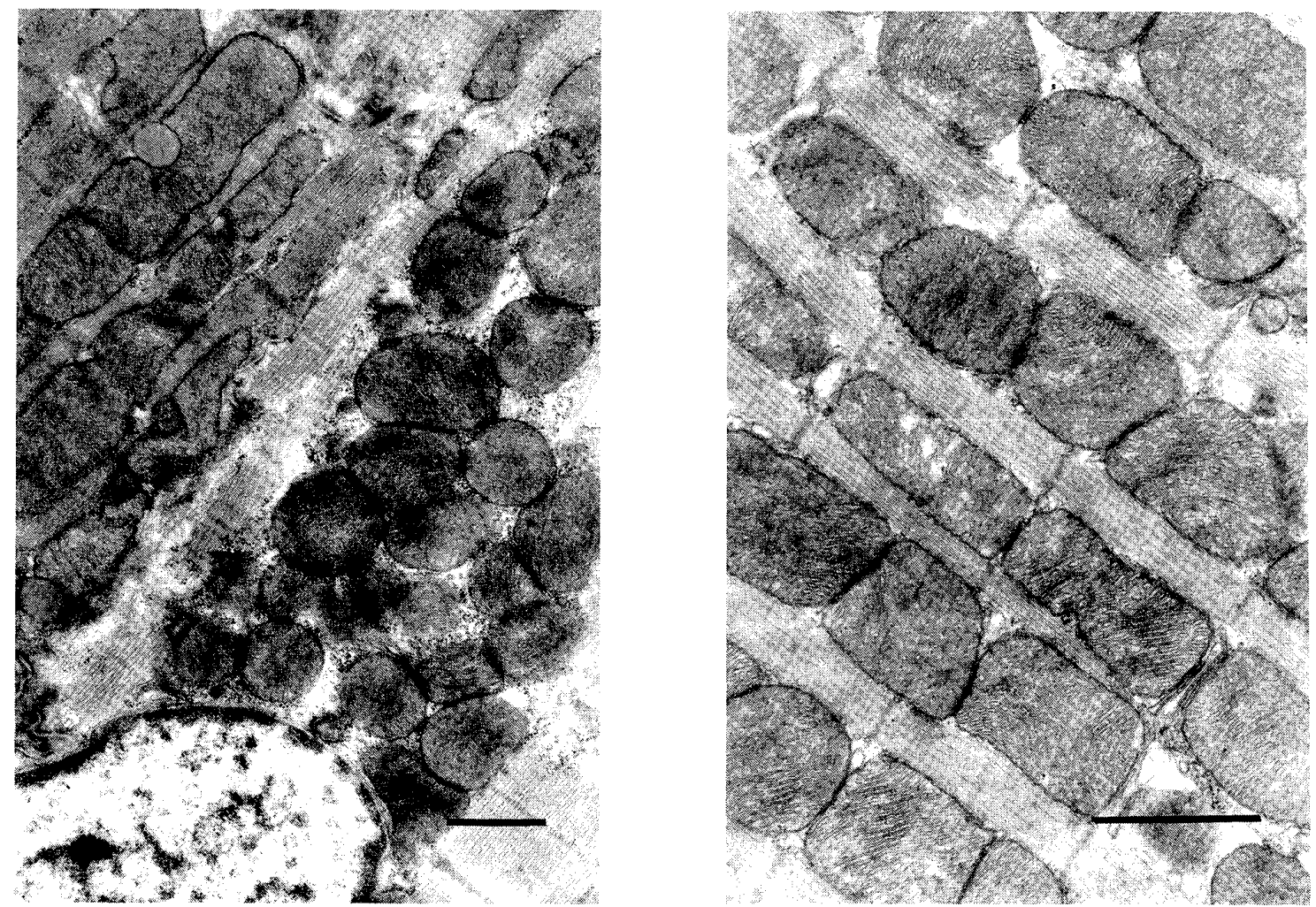

Fig.12. Electron micrograph showing left ventricular myocardial cell of adult rat during acute volume load by blood equalling the whole blood volume. Numerous enlarged mitochondria with increased number of cristae occupy a large intracellular space. $\mathrm{L}: \times 10000 ; \mathrm{R}: \times 17000$. Bar $=1 \mu \mathrm{m}$. 


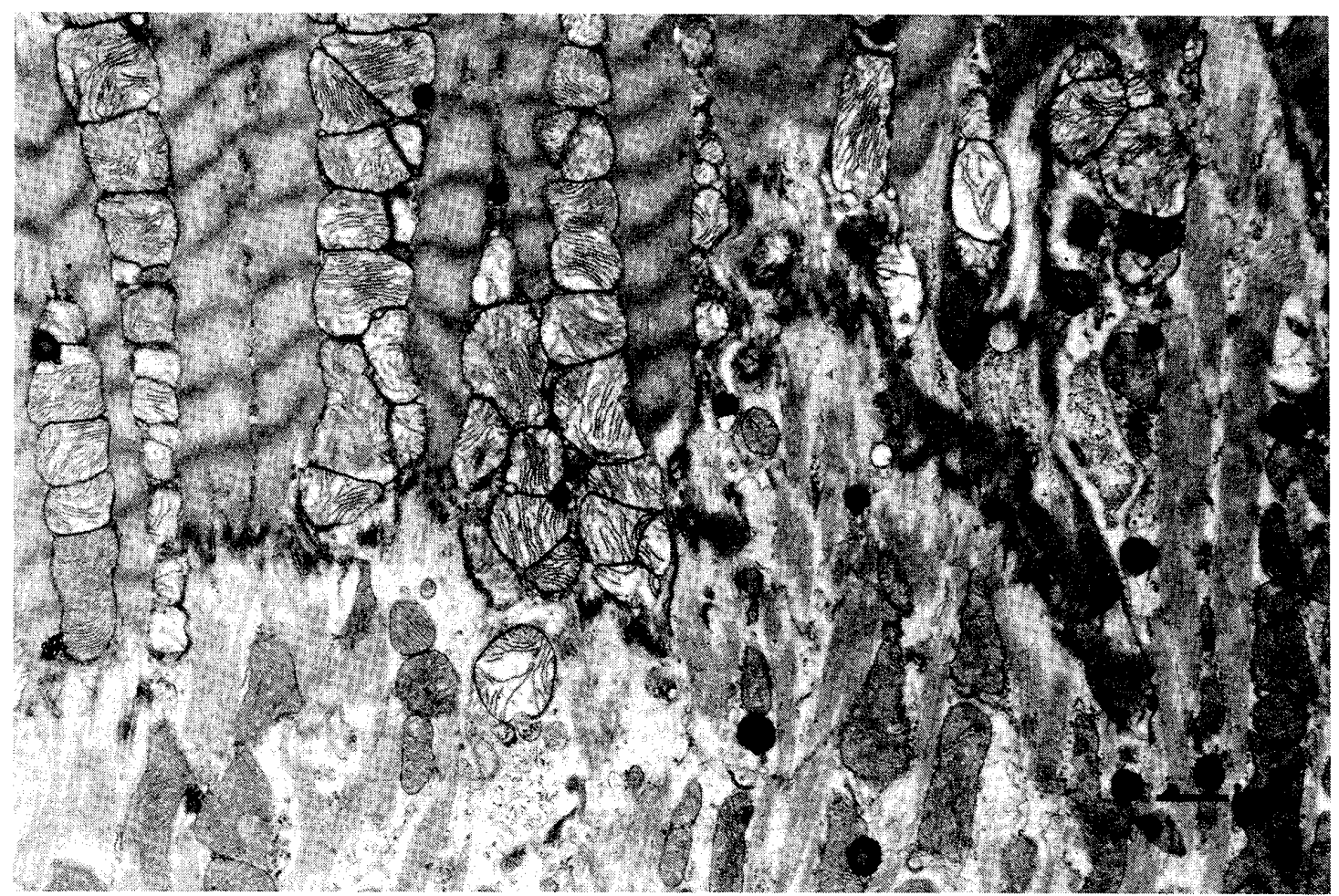

Fig.13. Electron mitrograph showing left ventricular myocardial cell of 6-month-old rat during acute volume load by blood equalling twice as much as the whole blood volume. Mitochondrial damage and intracellular edema are found markedly. $\times 7000$. Bar $=1 \mu \mathrm{m}$.

Myofibril

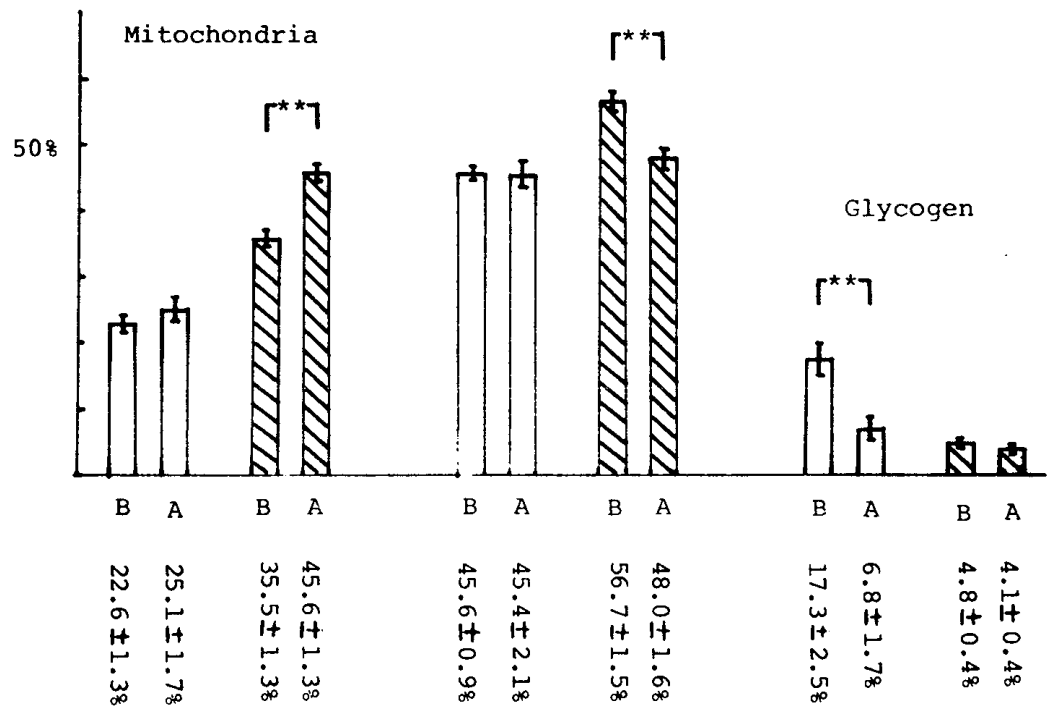

Fig.14. Comparison of morphometry in developing rat left ventricular myocardium before and after volume load. In young postnatal rat cardiac muscle, there are no significant differences in volume percentages of mitochondria and myofibrils found between control group and volume load group, also glycogen particles decrease significantly after volume load. However, in 90-day-old rat cardiac muscle, volume percentages of mitochondria increase markedly after volume load.

Short vertical lines represent standard error.

(ㅁ) 0-day-old rat (1-2 hours after birth); (\$ 90-day-old rat. $\mathrm{B}$ : before volume load, $\mathrm{A}$ : after volume load, ${ }^{* * \mathrm{P}}<0.01$. 
that great changes and proliferation of mitochondria occurred. The content of myofibrils in young post-natal rats of the volume load group was the same as that of the control group. However, the volume percentage of myofibrils in 90-day-old rat myocardium after volume load decreased significantly $(\mathrm{P}<0.01)$, although the true content of myofibrils may not have been altered. In 90-day-old cardiac muscle, the content of glycogen particles in the volume load group is as same as that in the control group. These results show that the matured cardiac muscle can adapt well to an abrupt volume load with proliferation of mitochondria, but the prematured cardiac muscle is damaged markedly by the same load.

\section{DISCUSSION}

According to Dawes' examination on lambs, the approximate volume of blood flow through the right atrium in a fetus is $200 \mathrm{ml} / \mathrm{kg} / \mathrm{min}$, and that through the left atrium is $130 \mathrm{ml} / \mathrm{kg} / \mathrm{min}$. Namely, the volume of blood flow through right atrium is one and a half times as much as that through the left atrium. The approximate volume of blood flow through the right ventricle in a fetus is $100 \mathrm{ml} / \mathrm{kg} / \mathrm{min}$, and that through the left ventricle is $130 \mathrm{ml} / \mathrm{kg} / \mathrm{min}$. Thus, the volume of blood flow through the left ventricle is 1.3 times as much as that through the right ventricle. For rats, a similar fetal circulation is suspected. After birth, foramen ovale and ductus arteriosus are closed spontaneously, ${ }^{1-3}$ and the volumes of each blood flow through both atria and both ventricles become the same. According to the examination by Dawes 5,6 or Cross, 8 cardiac output in lambs after birth may be about 3 times as much as that of the fetus. For rats, a similar increase is suspected. Furthermore, after birth, high pulmonary vascular resistance in the perinatal period lowers gradually with increasing age 2,12-14 In this way, great changes in circulation happen abruptly at birth, and also various volumes and pressures are loaded to both atria and both ventricles.

It is valuable to examine the ultrastructural changes of developing rat cardiac muscle during changes in circulation at birth. For the fine structures of developing rat cardiac muscle, some examinations have already been done, ${ }^{15-20}$ but nothing has yet been done about ultrastructural changes in both atria and both ventricles by considering changes in circulation at birth.

Therefore, I examined the fine structures of both atrial and both ventricular myocardiums during normal growth, and analysed them by the point counting technique. In the four chambers, no significant differences were found in th three main components (mitochondria, myofibrils and glycogen particles) at any age. Namely, in the cardiac muscle at day 0 , the mean content of mitochondria was 23 to $27 \%$, that of the myofibrils was 44 to $48 \%$, and that of the glycogen particles was 14 to $18 \%$. In the myocardium at day 7 , on the other hand, the mean volume percentage of mitochondria was 30 to $31 \%$, that of myofibrils was 47 to $49 \%$, and that of glycogen particles was 9 to $14 \%$. Thus, mitochondria increased prominently. In the myocardium at day 90 , the mean content of mitochondria was 32 to $36 \%$, that of myofibrils was 53 to $58 \%$, and that of glycogen particles was 4 to $8 \%$. Myofibrils increased prominently with activating movement.

These results show that the cardiac muscles of young postnatal rats utilize both glycogen and motochondria for energy metabolism, 21 but those of adult rats utilize mainly mitochondria as the most important energy source. Also, myofibrils and mitochondria develop prominently from day 7 to day 90 with increasing movement.

It is suspected that, at birth, the cell diameter of the left atrial myocardium is smaller than that of the right atrial, because in fetal circulation the volume load to the left atrium is smaller than that to the right. The cell diameter of the left atrial myocardium increases after birth with the increase of cardiac output and reaches the same size as that of the right atrial and right ventricular myocardium. But the cell diameter of the right atrial and right ventricular myocardium may not be altered for a week after birth, because the increased volume load due to the increase of cirdiac output and the decreased pressure load due to the decrease of pulmonary arterial resistance offset each other. But the cell diameter of the left ventricular myocardium increases because of increased volume load and pressure load after birth. After that period, the cell diameters of both atria and both ventricles become larger with increasing age; such a tendency is especially prominent in both ventricles, as they have stronger pressure load.

The cells of the left ventricle are the largest of the four chambers because the left ventricle has the biggest pressure load. Nuclear diameters do not alter significantly with increasing age, and those of both atria and both ventricles are same. This result shows that pressure and volume loads 
do not influence the development of nuclei.

In spite of pressure and volume loads accompanied with abrupt circulatory changes at birth, both damages of myofibrils and intracellular organs and intracellular edema were seldom seen. This shows that the young post-natal rat cardiac muscle has sufficient tolerance to these loads.

The cardiac muscle of young post-natal rats has poorly-developed myofibrils, a large number of glycogen particles and ribosomes, and rich rough-surfaced endoplasmic reticulums. After birth, synthesis and proliferation of myofibrils are performed abruptly during the pressure and volume load.

Autoradiographic study showed that a few mitoses were seen in cardiac muscle of 4-weekold rats? 22,23 I observed mitosis in cardiac muscle cells of an 8-day-old rat by electron microscopy, and confirmed cell proliferation after birth.

Much has been studied about the effects on the fine structures of adult cardiac muscles from various loads such as pressure, volume, exercise, carbon monoxide inhalation and the administration of various drugs? ${ }^{4-30}$ However, there has been no ultrastructural study about the differences in tolerance of volume load between young post-natal and adult rats. Also, there has been no quantitative analysis done for their differences by the point counting technique.

Thus, I examined the fine structures in the left ventricles of young post-natal and adult rats during acute volume load, and analysed them quantitatively. Swelling of mitochondria, destruction of cristae, separation of nuclear membrane, and intracellular edema were found markedly in the myocardium of the young postnatal rats during volume load. In the myocardium of adult rats during the same volume load, however, the above damages were only slightly found, and numerous enlarged mitochondria with an increased number of cristae occupied the larger intracellular space. These results show that the tolerance of post-natal cardiac muscle is lower than that of adult cardiac muscle. Such a poor tolerance is due to both the prematurity of intracellular structures and the further overload added to the cardiac muscle which has undergone abrupt circulation change at birth. This explanation of the cause of poor tolerance offers one of the reasons why cardiac failure easily happens in children with congenital heart diseases. Such diseases are ventricular septal defect, patent ductus arteriosus and total anomalous pulmonary venous return, where the left to right shunt increases abruptly with decreasing pulmonary arterial resistance in early infancy.

\section{SUMMARY}

1. In comparison with adult rats, the myocardial cells of young post-natal rats contain more ribosomes, glycogen particles and roughsurfaced endoplasmic reticulums, but fewer mitochondria and myofibrils.

The mean volume percentages of mitochondria in myocardial cells at day 0 are 23 to $27 \%$ in both atria and both ventricles, those of myofibrils are 44 to $48 \%$, and those of glycogen particles are 14 to $18 \%$.

2. In comparison with young post-natal rats, the myocardial cells of 7-day-old rats contain better-developed mitochondria and myofibrils, but fewer ribosomes, glycogen particles and rough-surfaced endoplasmic reticulums.

3. The volume percentages of mitochondria, myofibrils or glycogen particles in 3-month-old rats are almost the same as those of adult rats. Namely, the mean total areas occupied in the sarcoplasm by mitochondria in the four chambers are 32 to $36 \%$, those by myofibrils are 53 to $58 \%$, and those by glycogen particles are 4 to $8 \%$.

4. Thus, for the three main intracellular components; mitochondria, myofibrils, and glycogen particles; there are no significant differences among the mean contents in the four chambers at any age.

5. In spite of abrupt circulatory changes at birth, both damages of myofibrils and intracellular organs and intracellular edema are seldom seen in the myocardium of young post-natal rats. Such shows that the young post-natal rat cardiac muscle has sufficient tolerance to these natural loads.

6. Mitosis was found in the cardiac muscle cells of an 8-day-old rat and cell proliferation after birth was confirmed.

7. Throughout the developmental periods, the minimum diameters of the nuclei in both atria and both ventricles did not greatly alter to become significantly different.

8. The cell diameter of the left atrium of 0-dayold rats was significantly smaller than that of the right atrium, right ventricle or left ventricle. The cell diameters of the right atrium and right ventricle were not significantly altered until the 7 th day after birth, but that of the left atrium increased markedly for the same period, and then, became equal to that of the right atrium or right ventricle. Further, the cell diameter of the left 
ventricle increased markedly. After that period, the cell diameters of both atria and both ventricles increased prominently with increasing age. The increase was more prominent in the ventricular than in the atrial myocardiums.

9. Mitochondrial destruction and intracellular edema were found in the myocardium of young post-natal rats after volume load by blood equalling the whole blood volume. In the myocardium of adult rats during the same volume load, however, the above damages were only slight, and numerous enlarged mitochondria with increased number of cristae occupied a larger intracellular space. These results show that the tolerance of young post-natal cardiac muscle is poorer than that of adult cardiac muscle.

\section{Acknowledgement}

The author wishes to express sincere gratitude to Professor Tomoichi Kusunoki for his excellent guidance. The author further wishes to express his appreciation to Drs. Zenshiro Onouchi and Munehiko Tomisawa for their valuable guidance and suggestions.

The outline of this manuscript was reported at the seventh and eighth annual meeting of clinical electron microscopy society, also at the seventy-ninth annual conference of Japanese pediatric society.

\section{REFERENCES}

1. ADAMS, F. H. \& LIND, J.: Physiologic studies on the cardiovascular status of normal newborn infants. Pediatrics 19: 431, 1957.

2. ROWE, R. D. \& JAMES, L. S.: The normal pulmonary artery pressures during the first year of life. $J$. Pediat. 51: 1, 1957.

3. MOSS, A. J., EMMANOUILIDES, G., \& DUFFIE, E. R.: Closure of the ductus arteriosus in the newborn infant. Pediatrics 32: 25, 1963.

4. DAWES, G. S.: Changes in the circulation at birth. Brit. Med. Bull. 17 (2): 148, 1961.

5. DAWES, G. S. \& MOTT, J. C.: The increase in oxygen consumption of the lamb after birth. $J$. Physiol. 146: 295, 1959.

6. DAWES, G. S., JACOBSON, H. N., MOTT, J. C., \& SHELLEY, H. J.: Some observations on fetal and newborn rhesus monkeys. J. Physiol. 152: 271, 1960.

7. TAYLOR, P.: Oxygen consumption in newborn rats. J. Physiol. 154: 153, 1960.

8. CROSS, K. W., DAWES, G. S., \& MOTT, J. C.: Anoxia, oxygen consumption and cardiac output in newborn lambs and adult sheep. J. Physiol. 146: 316, 1959.

9. WEIBEL, E. R.: Stereological principles for morphometry in electron microscopic cytology. Intern. Rev. Cytol. 26: 235, 1969.

10. MOBLEY, B. A. \& PAGE, E.: The surface area of sheep cardiac purkinje fibers. J. Physiol. 220: 547, 1972.

11. KARNOVSKY, M. J.: A formaldehyde-glutaraldehyde fixative of high osmolality for use in electron microscopy. J. Cell. Biol. 27: 137A, 1965.
12. ADAMS, F. H., HIRVONEN, L., LIND, J., \& PELTONEN, T.: Physiologic studies on the cardiovascular status of newborn pigs: Effect of adrenaline, noradrenaline, acetylcholine and serotonin. Études néo-natales 7: 53, 1958.

13. RUDOLPH, A. M., AULD, P. A., GOLINKO, R. J., \& PAUL, M. H.: Pulmonary vascular adjustments in the neonatal period. Pediatrics 28: 28, 1961.

14. EMMANOUILIDES, G. C., MOSS, A. J., DUFFIE, E. R., \& ADAMS, F. H.: Pulmonary arterial pressure changes in human newborn infants from birth to 3 days of age. J. Pediat. 65: 327, 1964.

15. MELAX, H. \& LEESON, T. S.: Fine structure of developing and adult intercalated discs in rat heart. Cardiovasc. Res. 3: 261, 1969.

16. JAMES, T. N.: Cardiac conduction system: Fetal and postnatal development. Amer. J. cardiol. 25: 213, 1970.

17. PAGE, E., EARLEY, J., \& POWER, B.: Normal growth of ultrastructures in rat left ventricular myocardial cells. Circ. Res. (Suppl. II) 34 and 35: $12,1974$.

18. HIRAKOW, R. \& GOTOH, T.: A quantitative ultrastructural study on the developing rat heart. Developmental and physiological correlates of cardiac muscle, Vol. 1, p. 37, edited by M. Lieberman and T. Sano, Raven Press, New York, 1975.

19. LEGATO, M. J.: Ultrastructural changes during normal growth in the dog and rat ventricular myofiber. Developmental and physiological correlates of cardiac muscle, Vol. 1, p. 249, edited by M. Lieberman and T. Sano, Raven Press, New York, 1975.

20. ISHIKAWA, H. \& YAMADA, E.: Differentiation of the sarcoplasmic reticulum and T-system in developing mouse cardiac muscle. Developmental and physiological correlates of cardiac muscle, Vol. 1, p. 21, edited by M. Lieberman and T. Sano, Raven Press, New York, 1975.

21. SAKO, R.: Electron microscopic study of cardiac muscle of developing human embryo. Jap. Circul. $J$. 35: 1491, 1971. (in Japanese)

22. SASAKI, R., MORISHITA, T., \& YAMAGATA, S.: Mitosis of heart muscle cells in normal rats. Tohoku J. Exp. Med. 96: 405, 1968.

23. ZAK, R.: Cell proliferation during cardiac growth. Amer. J. cardiol 31: 211, 1973.

24. KAROW, A. M., SHLAFER, M., \& SIMS, R.: Contractile and Ultrastructural effects of hypothermia and of high pressure on rat hearts during ischemia. J. Surg. Res. 11: 571, 1971.

25. LAGUENS, R. P. \& Gómez-Dumm, C. L. A.: Fine structure of myocardial mitochondria in rats after exercise for one-half to two hours. Circ. Res. XXI: 271, 1967.

26. FERRIER, R. W., SEKHON, S. S., STEMMER, E. A., \& CONNOLLY, J. E.: Ultrastructural changes in the heart during acute failure. J. Thorac. Cardiovasc. Surg. 63: 882, 1972.

27. HATT, P. Y. \& MORAVEC, J.: Acute hypoxia of the myocardium: Ultrastructural changes. Cardiology 56: 73, 1971/1972.

28. SUZUKI, T.: Effects of carbon monoxide inhalation on the fine structure of the rat heart muscle. Tohoku J. Exp. Med. 97: 197, 1969. 
29. SHARMA, G. P., VARLEY, K. G., KIM, S. W., BARWINSKY, J., COHEN, M., \& DHALLA, N. S.: Alterations in energy metabolism and ultrastructure upon reperfusion of the ischemic myocardium after coronary occlusion. Amer. J. Cardiol. 36: 234,1975 .
30. SMITH, H. E. \& PAGE, E.: Morphometry of rat heart mitochondrial subcompartments and membranes: Application to myocardial cell atrophy after hypophysectomy. $J$. Ultrastruct. Res. 55: 31 , 1976. 